\title{
Ambiente violento, infância perdida?
}

Ana Carolina Dias Vieira*1

Silvia Maria Abu-Jamra Zornig*2

\begin{abstract}
$O$ objetivo deste artigo é investigar a constituição emocional e psíquica de crianças de duas favelas do Rio de Janeiro, onde são constantemente expostas a uma realidade de medo, terror e desamparo, e o potencial traumático precisa ser considerado. Baseado em uma prática clínica ampliada desenvolvida com essas crianças, o artigo discute o papel da hospitalidade e empatia fornecidas pela comunidade que parecem contribuir para um desenvolvimento saudável. Um desenvolvimento emocional precoce, no entanto, pode ser observado como medida de proteção desenvolvida pelas crianças numa tentativa de "sabiamente cuidar de si".
\end{abstract}

Palavras-chave: Infância, trauma, psicanálise, maturidade precoce

*1 ONG Casa da Árvore (Rio de Janeiro, RJ, Br).

*2 Pontifícia Universidade Católica do Rio de Janeiro - PUC-Rio (Rio de Janeiro, RJ, Br). 
A realidade da maioria das favelas do Rio de Janeiro é de um enorme desamparo social e de muita violência. Um ambiente dominado pelo tráfico, que presencia diariamente a guerra e os conflitos pelo poder e pontos de venda de drogas. Sabe-se que quem sofre primeiramente as consequências deste cenário são os moradores das comunidades que vivem sob o medo e o terror que é gerado.

No dia a dia do trabalho da ONG Casa da Árvore, notamos que, apesar do ambiente adverso, as crianças que nos procuram são criativas, brincam e possuem recursos simbólicos e de elaboração. Diferente do que muito se acredita, mesmo diante de toda a violência contida no ambiente, existe vida e saúde coexistindo com o medo e o terror.

Diante disto, nos questionamos sobre como se constitui um sujeito dentro deste ambiente. Quais as condições de subjetivação dos sujeitos que vivem em situações difíceis e cercados por muita violência, instabilidade e descontinuidade?

\section{A comunidade e a infância, um encontro produtor de sentido}

A noção de trauma perpassa a teoria psicanalítica e pode ser pensada sob uma ótica psicopatológica ou sob uma perspectiva estruturante, constituinte do psiquismo. As contribuições de Ferenczi (1933/1992c) apontam para a ideia de que qualquer relação que invada, exceda e mobilize o psiquismo do sujeito pode ser concebida como traumática. No entanto, o autor ressalta que tal excesso e mobilização encontram-se em todas as relações, incluindo a relação mãe-bebê, que também possui seu potencial traumático. Assim, o autor propõe a compreensão de que os efeitos do trauma não se restringem à desestruturação do psiquismo, pois dentro de um limite a traumatização é importante para que haja uma constituição psíquica saudável, para que o sujeito seja impulsionado em direção à vida. 
O que definirá se o traumático será estruturante ou desestruturante serão os destinos deste trauma, eles podem ser "vitalizantes ou devastadores" (Figueiredo, 2003). Seu destino dependerá da intensidade do evento, da capacidade narcísica e egoica do indivíduo de lidar com a mesma e do ambiente e "seu modo de estar presente".

Para a elaboração do trauma é fundamental a presença de um outro que testemunhe. Recorrendo à noção de "sentir com" de Ferenczi (1931/1992b) podemos apontar que a presença do outro e seu testemunho são fundamentais na elaboração e amenização do traumático. Para que não haja o desmentido, fator considerado por Ferenczi (1933/1992c) como responsável pelo êxito traumático, é necessária a presença de um outro que dê validade ao evento.

É possível descrever as funções antitraumáticas como aquelas que, cumpridas por um outro, possibilitam um bom funcionamento psíquico (Cintra, 2003). A dimensão antitraumática dessas funções está no fato de que auxiliam o sujeito a superar as dificuldades na adaptação à realidade do mundo externo.

Durante o processo de desenvolvimento e de adaptação à realidade do mundo externo, o bebê sofre frustrações e desilusões que são necessárias para sua estruturação. No entanto, se estas frustrações e os sentimentos de desprazer vividos forem excessivos, podem se tornar potencialmente traumáticos, dificultando a adaptação do bebê. Neste sentido, a função desempenhada pelo objeto primário possui um 90 papel muito importante para que este processo não se constitua enquanto traumático (Vieira \& Zornig, 2011).

No dia a dia da Casa da Árvore presenciamos situações nas quais é possível notar um cuidado por parte dos adultos, e dos moradores em geral, com as crianças. É comum presenciarmos pessoas que passando por nós, durante os plantões, perguntam às crianças sobre a escola, o reforço escolar, sobre os irmãos e pais. Há uma preocupação constante com as atividades e com a rotina dessas crianças.

Nos relatos que nos chegam e no nosso dia a dia, é possível observar que a dinâmica do cuidado aparece de forma particular. Há muitos casos de famílias que, para ajudar no cuidado e na educação, acolhem crianças ou filhos de vizinhos que necessitem. Não é difícil ter conhecimento de histórias em que crianças vivam com outras famílias ou outros cuidadores que não sejam seus pais ou parentes mais próximos. $\mathrm{O}$ que ocorre, algumas vezes, mesmo com a presença dos pais na comunidade.

As crianças, por sua vez, também se mostram muito próximas e cuidadosas umas com as outras. É frequente termos informações sobre uma criança específica a partir da fala e das histórias trazidas pelas outras. Elas chegam nos contando o que aconteceu durante a semana, porque aquela tal criança não veio, se ocorreu algo em sua casa, entre outras situações. Além disso, é curioso observar que muitas vezes se identificam como tendo entre elas vínculos familiares quando não o possuem verdadeiramente. 


\section{ARTIGO}

É muito comum na Casa da Árvore receber crianças que se apresentam como sendo prima ou irmã de outra. Na tentativa de investigar e até mesmo de ajudá-los a compreender um pouco mais sobre suas histórias, sempre perguntamos sobre a origem deste parentesco. Se seus pais são irmãos, se são filhos do mesmo pai ou da mesma mãe, se moram na mesma casa. Frequentemente percebemos, ao longo das respostas e da costura que vamos fazendo delas, que o vínculo não é sanguíneo, mas puramente afetivo. Muitas vezes por viverem na mesma casa ou próximos uns dos outros, passam a maior parte do seu tempo, seja na escola, seja quando estão brincando, acompanhados dessas outras crianças. Parece ser este o sentido de família para elas.

Acreditamos que o que ocorre nas comunidades não é uma substituição das funções parentais, mas que as relações construídas funcionem como uma extensão dos cuidados originais. Dessa forma, podemos pensar que, apesar de as crianças não possuírem vínculos familiares, o vínculo afetivo se apresenta forte o suficiente para que haja uma identificação parental.

Este movimento de cuidado e atenção nos permite refletir sobre a comunidade possuir, possivelmente, um papel imprescindível na garantia e manutenção da saúde dos sujeitos que ali vivem. Através do afeto e das relações de cuidado entendemos que este ambiente pode ser capaz de cumprir uma importante função, uma função antitraumática.

De acordo com Figueiredo (2007/2009), o cuidar é fundamental na constituição psíquica do sujeito, possibilita o "fazer sentido", a assimilação e elaboração das vivências inerentes à existência humana. $\mathrm{O}$ agente de cuidado possui como função acolher, hospedar, agasalhar e alimentar e, cumprindo adequadamente seu papel, fornece um sentimento de continuidade, seja ela somatopsíquica ou relacionada às referências identitárias e simbólicas.

O desamparo encontrado nas favelas do Rio de Janeiro é conhecido por todos. A presença constante da violência gera insegurança e medo diariamente. Além de um ambiente tomado pelo risco, as favelas possuem uma escassez de ações do Estado que auxiliem no sustento básico das famílias.

Diante deste cenário de desamparo e dos arranjos particulares que são verificados nas relações familiares citados anteriormente, podemos traçar uma relação entre o potencial traumático e os arranjos observados? Notamos que essas figuras de cuidado são evocadas também devido a essa situação de extrema precariedade. Os laços sociais parecem estreitar-se diante da necessidade de um cuidado e atenção de todos constantemente.

De acordo com o que foi apontado por Plastino (2009) em seu artigo "A dimensão constitutiva do cuidar", um lugar para se viver significa um lugar para ser, um ambiente que é condição para a emergência do ser. É no "nós", na morada, na pátria que o indivíduo pode construir sua singularidade. É o reconhecimento 
mútuo, o pertencimento a um coletivo, o ser parte de uma comunidade que possibilita o vir a ser humano e de sua singularidade.

Neste sentido, utilizando o conceito de comunidade como identidade, paridade e conformidade (http://www.priberam.pt/dlpo/), podemos pensar nas identificações, na demanda que é comum aos membros da favela. É possível notar como pertencente a todos os que ali vivem, adultos e crianças, uma necessidade de assimilação da realidade vivenciada. Angústias e sofrimentos são afetos experimentados por todos diante da realidade de violência. Segundo Kupermann (2009), a afetação mútua surge como propiciadora de um lugar de acolhimento e segurança. A empatia permite que o lugar de cuidador seja ocupado, fortalecendo os laços sociais.

É este o lugar que acreditamos que a comunidade e as relações se apresentem, como um outro que testemunha e propicia o fazer sentido da situação traumática. A hospitalidade da comunidade parece se presentificar na contramão da hostilidade do ambiente. Considerando que é a partir da empatia que se torna possível exercer o lugar de cuidador somado à noção de afetação mútua, apontando para uma comunidade que se identifica quanto às suas demandas e ao lugar que ocupa na sociedade, a empatia da comunidade é localizada como um fator que proporciona o fortalecimento dos laços sociais e o cuidado entre os moradores.

Entendemos a comunidade como este coletivo que auxilia o sujeito no processo de elaboração do potencial traumático do ambiente em que vivem, os laços sociais mais estreitos fornecerão a confiança e a possibilidade de fazer sentido. A noção de comunidade, considerada como este todo que se identifica, que é afetado mutuamente e que possui uma mesma linguagem, possibilita concebermos a existência de um encontro de línguas entre a demanda da infância e a comunidade, um "encontro produtor de sentido". Este encontro, que fornece confiança, tenta, então, contornar o desencontro entre a violência e o desamparo existentes no ambiente com o mundo infantil.

Como apontamos, portanto, entendemos que as relações afetivas dentro das comunidades são o que torna possível que o efeito traumático da violência das favelas seja amenizado quanto ao seu potencial desestruturante. A comunidade como um agente cuidador fornece a sustentação suficiente para moderar o sofrimento e possibilitar o continuar a ser do sujeito.

\section{A maturidade precoce e a sabedoria como possibilidade de existência}

Refletindo sobre a realidade das favelas e em como é viver neste ambiente, se faz necessária uma reflexão a respeito de seus efeitos no psiquismo dos sujeitos. Para tanto, é preciso considerar o potencial traumatizante que este ambiente possui. 


\section{ARTIGO}

Como já apontamos, viver nas favelas é um constante risco, é estar em contato, diariamente, com o medo e a insegurança. $\mathrm{O}$ medo de não chegar à casa ou à escola, o medo de não ver os pais voltarem, o medo de que entrar para o crime seja sua única opção na vida, faz parte da realidade das crianças que vivem nas comunidades dominadas pelo tráfico de drogas.

Desta forma, sem deixar de lado a questão colocada anteriormente, sobre o papel da comunidade, é preciso reconhecer que o ambiente da favela é de muita precariedade. Não apenas pela presença do tráfico de drogas, mas também pela ausência de assistência social e financeira.

O poder do tráfico armado e os constantes conflitos com a polícia e as facções rivais, situações recorrentes em comunidades ocupadas pelo tráfico, fazem com que este cenário tenha como personagens principais - mortes, tiros e muita crueldade. Todo este contexto expõe uma imensa parte da população aos perigos e consequências do conflito armado. Esta realidade é vivida, devido à lei do silêncio que é ditada pelo poder do tráfico, de forma passiva pela comunidade. Existe neste ambiente uma atmosfera de negação ou emudecimento das reações emocionais à violência.

Além disso, a situação social que se vivencia nessas comunidades está muito distante do que chamaríamos de adequada. A condição financeira desta população não é suficiente para que, sem ações sociais, sejam garantidos bens de consumo básicos para o sustento da família, para uma moradia decente e o acesso à saúde. Ao mesmo tempo, as políticas e ações públicas de assistência a essa população são bastante precárias.

Dentro do contexto que foi descrito, há uma infância que vive, presencia e que é exposta a toda esta realidade. Na Casa da Árvore, trabalhamos com crianças que nos apresentam questões e preocupações muito precoces e excessivas. É exigido delas um tipo de organização na qual, muitas vezes, não é possível sentir medo, tampouco reclamar a irresponsabilidade da infância. Frequentemente, são elas, as responsáveis e cuidadoras da casa e dos que as rodeiam. Se desenvolver precocemente parece ser necessário para que se possa sobreviver às adversidades do ambiente em que estão inseridas.

É natural que na infância as crianças vivam experiências de terror e medo, mas dentro de um limite e tendo sempre ao seu lado adultos que deem um contorno e as ajudem a dar sentido a essas vivências. No entanto, como é muito bem apontado por Golomb em "Terror na infância" (2003/2008) quando "esses escudos protetores são rompidos, a criança tem que se desenvolver em condições adversas sem a plena sustentação da família e da comunidade, já que estas estão também ameaçadas; e ela adquire defesas adultas como parte de seu dia a dia" (p. 197). Ao invés de sentirem que há um mundo adulto que está presente para ajudá-las em seu caminho, elas têm de servir às necessidades deste mundo. As crianças precisam adquirir 
defesas adultas para se desenvolver, uma vez que a família, assim como as próprias crianças, vive ameaçada neste ambiente tão adverso e não pode fornecer uma sustentação plena.

Ferenczi (1933/1992c) é um autor que trabalhou este tema e contribui para a nossa investigação. A maturidade precoce, concebida pelo autor, é teorizada como um tipo de organização psíquica decorrente de um trauma. Ferenczi aponta que se não houver uma dominação da fragmentação, inevitavelmente causada pelo trauma, ocorre a instalação de um supereu não assimilado, chegando assim a uma forma de personalidade clivada, feita unicamente de id e supereu, que não se afirma nem em caso de desprazer.

O supereu não assimilado é para Ferenczi ([1927]1928/1992a) um supereu constituído por transplantes estranhos (conteúdos externos causadores de desprazer), leis e proibições arbitrárias que são introjetados (por exemplo, a culpa não reconhecida pelo adulto) pelo agredido durante a situação em que ocorreu o trauma. Desta forma, o supereu é concebido como o lugar intrapsíquico ocupado pelo agressor. Para o autor, o êxito do trauma, assim como a consequência do desmentido, é a clivagem ou cisão da personalidade. O supereu não assimilado não se integra ao resto da estrutura do sujeito. "A severidade excessiva pode acarretar prejuízos para a criança por toda a vida, dotando-a de um superego demasiado rígido” (p. 12).

Como consequência da constituição cindida, tendo como componente psíquico o supereu não assimilado, Ferenczi (1933/1992c) aponta, em "Confusão de línguas entre os adultos e a criança", para dois "tipos" de personalidades desenvolvidas pelos sujeitos. De um lado, uma personalidade regressiva, na qual se encontra um sujeito que sofreu uma transformação, passou de criança terna a um ser traumatizado, culpado, introjetando a culpa do adulto. $\mathrm{O}$ sujeito obedece mecanicamente a "vontade estranha" (decorrente dos transplantes estranhos) do agressor, que neste momento é integrante de sua própria personalidade. "A criança de quem se abusou converte-se num ser que obedece mecanicamente, ou que se fixa numa atitude obstinada; mas não pode mais explicar as razões dessa atitude” (p. 103).

O outro tipo de personalidade é a progressiva, em que o sujeito traumatizado é obrigado a amadurecer precocemente na tentativa de lidar com os transplantes estranhos, uma "progressão traumática", denominada por ele de "bebê sábio".

Além desses dois "tipos" de personalidades encontradas no texto de Ferenczi, o autor indica um terceiro meio de "prender" a criança apontado como "terrorismo do sofrimento". A criança, diante de uma incapacidade dos pais de lidar com seus problemas, assume certos papéis que não dizem respeito a ela. Obrigações que deveriam ser assumidas pelos pais, passam a ser responsabilidade do filho, que cumpre o que é pedido na tentativa de manter o vínculo e poder desfrutar de uma ternura anterior. A criança se torna assim um auxiliar dos pais, um substituto materno. O êxito do processo traumático resulta em um sujeito cindido, 


\section{ARTIGO}

transformando "um ser que brinca espontaneamente, e com toda inocência, num autômato, culpado do amor, e que, imitando ansiosamente o adulto, esquece-se por assim dizer de si mesmo" (p. 106).

Muitas das famílias que chegam à Casa da Árvore, por viverem imersos nesta realidade das favelas, são, muitas vezes, desejantes de cuidados. Os pais possuem, em sua maioria, a necessidade de deixar sua função para retornar ao trabalho e dar conta do sustento. Desta forma, confiam suas crianças aos cuidados de parentes, vizinhos ou irmãos mais velhos que cumprem esse papel. As crianças desde muito cedo se responsabilizam por seus irmãos mais novos e pela casa.

Como aponta Milman (comunicado em conferência, 26 de setembro, 2009), toda essa situação vivida influencia o modo de cuidar e estar com os filhos, não é possível e, muitas vezes, permitido brincar, conversar, doar um tempo maior às crianças. A infância passa a ser um período que não é muito valorizado, não é visto como uma época que necessita de atenção e cuidado especiais.

O desamparo vivido pela comunidade ao mesmo tempo em que, como apontamos anteriormente, é fortalecedor dos vínculos sociais, é o motivo pelo qual há uma impossibilidade de cuidado e dedicação maior às crianças. A "violência estrutural", existente no ambiente, apreende esse cuidador que, de alguma forma, se encontra impossibilitado de exercer suas funções. Este adulto, que poderia ajudar na elaboração e na assimilação do excesso, não encontra condições de fazê-lo.

Sendo assim, sem esquecer o tema trazido sobre a comunidade que possui um potencial de contenção para esse excesso vivido, e assim uma função antitraumática em relação ao que há de agressivo e violento no ambiente; é preciso reconhecer que esse mesmo contexto violento deposita uma grande e excessiva responsabilidade sobre as crianças e, desta forma, exige-se das mesmas que se desenvolvam e se movimentem em direção à vida, amadurecendo precocemente.

\section{Amadurecimento precoce: uma forma de subjetivação?}

Para a continuidade e melhor compreensão do tema da maturidade precoce em relação ao contexto que estamos trazendo, introduziremos uma importante discussão. Quando abordamos a questão do amadurecimento precoce, buscamos tratar a mesma sem que se encerrasse em uma categorização de uma estrutura saudável ou patológica. Sendo assim, onde se localiza e como se caracteriza o que estamos apontando?

Para a psicanalista T. Pinheiro, em Ferenczi: do grito à palavra (1995), é devido ao esforço para superar o sofrimento e a angústia decorrentes do trauma que a maturidade é adquirida. Quando foi preciso, o sujeito teve a "sabedoria de progredir 
traumaticamente". Pinheiro (1995) aponta o amadurecimento como tendo uma função protetora. Segundo a autora é a ela que cabe a tarefa de ficar atenta e antecipando-se para não ser mais surpreendida e amedrontada. "Sabedoria de estar ao mesmo tempo dentro e fora. Tantas medidas a tomar, tantas coisas para supervisionar, ela é como uma máquina que, para funcionar direito, deve estar longe das emoções (...)" (p. 96).

E é nesta direção que gostaríamos de abordar a questão do amadurecimento precoce. Para continuar em direção à vida, o sujeito recorre a mecanismos de defesa e a estratégias para lidar com a desorganização psíquica e social. Acreditamos que a maturidade precoce se desenvolva, neste sentido, enquanto uma estrutura que busca a integração e alguma possibilidade de existência. De acordo com Maia (2009), em um ambiente que não oferece estabilidade os projetos de vida se constroem levando em consideração estratégias de proteção para a integridade do eu.

No dia a dia da Casa da Árvore vivenciam-se situações em que as crianças apresentam de forma clara a questão do amadurecimento precoce. Um exemplo disto está no fato delas se apresentarem, na Casa da Árvore e em suas vidas, como protagonistas e relatores de suas histórias. É muito difícil que os pais acompanhem seus filhos, o mais comum é que as crianças venham sozinhas ou acompanhadas por outra um pouco mais velha. "Os adultos que fazem parte da construção psíquica da criança, cuja presença Dolto julgava indispensável, marcam presença junto a seus filhos de outra forma, longe de nós" (Milman, 2009, p. 255).

$\mathrm{O}$ fato de as crianças participarem ou circularem sozinhas pela comunidade pode ser perturbador e angustiante em muitos momentos. No entanto, de acordo com o que apontamos sobre a comunidade e as relações que naquele ambiente se constroem, fica mais acessível a ideia de que crianças passem a maior parte de seu tempo "soltas" pelo espaço da favela. O cuidado que é fornecido pela comunidade e a necessidade dos pais de se ausentarem de suas funções permitem a compreensão da chegada desacompanhada à Casa da Árvore.

Desta forma, como indica Milman (comunicado em conferência, 26 de setembro, 2009), na Casa da Árvore se trabalha com crianças sem a presença e consequentemente o discurso de seus pais. As crianças precisam se apropriar de suas histórias e os psicólogos precisam trabalhar com isso que lhes é oferecido. $\mathrm{O}$ trabalho existe e é feito a partir do discurso desses pequenos sujeitos, ajudando-os a construir e dar sentido às suas vivências. Eles se responsabilizam por contar ao mundo suas experiências e suas origens.

A maioria das crianças que frequentam a Casa da Árvore possuem as peles marcadas por muitas cicatrizes e feridas. Essas feridas, na maioria das vezes, saram sozinhas, não há o auxílio de qualquer medicamento ou instrumento de primeiros socorros. A partir de suas falas, é possível notar que muitas vezes em suas casas faltam esses instrumentos, é um privilégio para alguns deles as ferramentas que são utilizadas para proteger e cuidar dos machucados. 


\section{ARTIGO}

Quando uma criança se fere durante os plantões, é utilizado um kit de primeiros socorros (mertiolate, água oxigenada, band-aid entre outros recursos) para tratar dos machucados. Nestes momentos, é muito comum que as crianças perguntem aos profissionais como aprenderam a fazer isso ou se são pais e mães de alguém. Frequentemente, elas fingem estar machucadas ou, ao ver outra criança sendo cuidada, pedem para que façam curativos e para tratar das cicatrizes e marcas existentes há tempos.

Acreditamos que esse processo de cicatrização de seus machucados possa ser comparado à situação que vivem. Assim como apresentamos a questão da maturidade precoce como sendo uma estrutura que foi desenvolvida para dar conta de um excesso traumático, esses ferimentos, à sua maneira, dão conta de cicatrizar suas dores. Sem cuidados extras, sem um outro ao seu lado auxiliando constantemente na elaboração de seus conflitos e angústias, eles encontram uma forma de cicatrizar suas feridas.

Recorremos à origem da palavra "pensar" e verificamos que dentre os seus sinônimos está o verbo "cuidar". Sua definição é vasta, mas uma delas é interessante para o tema que está sendo tratado, "fazer curativo" (http://www.priberam.pt/dlpo/). Segundo Figueiredo (comunicado em conferência, 12 de novembro, 2010), pensar é tratar cuidadosamente, adequadamente, convenientemente. A partir disto, acreditamos ser possível abordar o amadurecimento precoce como a aplicação de um curativo. Amadurecer antes do tempo adequado é também uma forma de, sabiamente, cuidar de si, de "fazer curativo" nas feridas internas, subjetivas, vividas pelo sujeito.

Ao mesmo tempo, sem o cuidado e auxílio necessários no processo de cicatrização, tanto os conflitos da infância quanto as feridas deixam suas marcas no corpo dessas crianças. Assim como o desmentido teorizado por Ferenczi, a falta do outro que fornece o contorno e o sentido aos eventos traumáticos, pode deixar marcas para o resto da vida.

Como apontado anteriormente, quando tratamos do amadurecimento precoce das crianças com as quais trabalhamos na Casa da Árvore, não nos aprofundamos na distinção da mesma enquanto uma estrutura saudável ou patológica. Tratamos da questão da maturidade precoce como consequência de um trauma desestruturante, uma estrutura desenvolvida em decorrência do excesso vivido. No entanto, apontamos que esta seria uma estratégia utilizada pelos sujeitos na tentativa de lidar com a desorganização psíquica e social buscando a integração e alguma possibilidade de existência.

Acreditamos que a maneira como concebemos o amadurecimento precoce dentro deste ambiente, uma busca por integração e vida, deve ser visto como algo positivo e criativo. $\mathrm{O}$ amadurecimento precoce observado dentro das comunidades em que a Casa da Árvore atua parece ser uma forma de dar sentido e contorno ao excesso. Se desenvolver-se prematuramente é um recurso para lidar com tal cenário, 
e que possuí-lo talvez pudesse ser mais danoso e prejudicial a esses sujeitos, sem isso é provável que nos deparássemos com uma desintegração devastadora.

Para finalizar, recorrendo às contribuições ferenczianas (1933/1992c), notamos que a relação entre a infância e a comunidade é uma relação de confiança que oferece saúde e continuidade, fatores importantes para que seja possível se colocar de forma criativa no mundo. A relação de confiança, o encontro de línguas entre a demanda infantil e o cuidado oferecido pela comunidade, fornece um ambiente onde o indivíduo pode se entregar ao outro e às relações sem o constante medo das perdas e de frustrações. No entanto, notamos também que o excesso que não corresponde à maturidade psíquica do sujeito e a impossibilidade dos adultos de se oferecerem como escudos protetores faz com que, em alguns momentos, esta confiança seja rompida.

Sendo assim, a partir do que apontamos sobre o amadurecimento precoce ser uma consequência do desamparo social e também um recurso utilizado pelo sujeito para dar conta do mesmo, e sobre a função antitraumática da comunidade e das relações ali existentes, é necessário retomar uma importante questão: Como solucionar o paradoxo função antitraumática da comunidade e a maturidade precoce como marca de um trauma desestruturante?

Acreditamos que as relações de cuidado existentes dentro das comunidades 98 são capazes de amenizar o potencial traumático do cenário de desamparo e que exercem uma função antitraumática. No entanto, como consequência e a fím de dar conta desta mesma realidade, o sujeito lança mão de uma estratégia de subjetivação, amadurecendo precocemente. Como muito bem foi colocado por Pinheiro, houve neste momento a "sabedoria de progredir traumaticamente".

A comunidade e os cuidados primários conseguem dar conta de amenizar o efeito devastador do ambiente violento, mas, ao mesmo tempo, por estarem inseridos e compartilharem esta realidade, possuem suas "mãos atadas" e estão impossibilitados de servirem de escudo protetor para suas crianças, defendendo-as do potencial traumático existente. Os pais e a comunidade como um todo são vítimas da mesma realidade vivida pelas crianças.

Ao mesmo tempo, a impossibilidade dos pais de exercerem os cuidados necessários de uma maneira mais eficiente, não significa que os cuidados e a contenção que puderam proporcionar não foram suficientes. Ao contrário, acreditamos que a sustentação fornecida impediu que algo de mais grave ocorresse. Indo além, assim como estes pais foram suficientemente cuidadosos a ponto de proteger seus filhos de consequências mais devastadoras, as crianças também desenvolvem formas e recursos para dar conta do que não pode ser contido, sendo sabiamente protetoras de si mesmas. 


\section{ARTIGO}

\section{Referências}

Cintra, E. M. (2003). As funções antitraumáticas do objeto primário: Holding, Continência e Rêverie. Tempo psicanalítico, 35, 37-55.

Ferenczi, S. ([1992a). A adaptação da família à criança. In S. Ferenczi, Obras Completas. Psicanálise IV (pp. 1-14). São Paulo: Martins Fontes. (Trabalho original publicado em 1927-1928).

Ferenczi, S. (1992b). Análise de crianças com adultos. In S. Ferenczi, Obras Completas. Psicanálise IV (pp. 69-83). São Paulo: Martins Fontes. (Trabalho original publicado em 1931).

Ferenczi, S. (1992c). Confusão de língua entre os adultos e a criança. In S. Ferenczi, Obras Completas. Psicanálise IV (pp. 97-108). São Paulo: Martins Fontes. (Trabalho original publicado em 1933).

Figueiredo, L.C. (2003). O paciente sem esperança e a recusa da utopia. In Elementos para a clínica contemporânea (pp. 159-189). São Paulo: Escuta.

Figueiredo, L.C. ([2007] 2009). As diversas faces do cuidar: considerações sobre a clínica e a cultura. In M. Maia (Org.), Por uma ética do cuidado (pp. 121-140). Rio de Janeiro: Garamond.

Figueiredo, L.C. (2009). As diversas faces do cuidar: novos ensaios de psicanálise contemporânea. São Paulo: Escuta.

Golomb, A. (2008). Terror na infância. In Varnin, Sverre e Volkan, D. Vamik (Orgs.), Violência ou diálogo? (pp. 187-197). São Paulo: Perspectiva. (Trabalho original publicado em 2003).

Kupermann, D. (2009). Figuras de cuidado na contemporaneidade: testemunho, hospitalidade e empatia. In M. Maia (Org.), Por uma ética do cuidado (pp. 185-204). Rio de Janeiro: Garamond.

Maia, M. (2009). Crianças do porão: descuido, violência psíquica e cuidado. In M. Maia (Org.), Por uma ética do cuidado (pp. 357-377). Rio de Janeiro: Garamond.

Milman, L. (2009). Casa da Árvore: um delicado encontro entre adultos do asfalto e crianças da favela. In M. Maia (Org.), Por uma ética do cuidado (pp. 251-267). Rio de Janeiro: Garamond.

Pinheiro, T. (1995). Ferenczi: do grito à palavra. Rio de Janeiro: Jorge Zahar/Ed. UFRJ.

Plastino, C. A. (2009). A dimensão constitutiva do cuidar. In M. Maia (Org.), Por uma ética do cuidado (pp. 53-87). Rio de Janeiro: Garamond.

Vieira, A. C., \& Zornig, S. (2011). Ambiente violento, infância perdida? Dissertação de mestrado, Pontifícia Universidade Católica, Rio de Janeiro, RJ, Brasil.

\section{Resumos}

(Violent environment, lost childhood?)

The main purpose of this paper is to analyze the emotional and psychic constitution of children living in poor communities of Rio de Janeiro, where they are constantly 
exposed to extreme violent situations and feelings of helplessness, fear and despair, as well as a potential trauma. Based on a clinical practice developed with these children, the paper discusses the role of hospitality and empathy provided by the community that seems to contribute for their healthy development. Nevertheless, a precocious emotional development has been observed as a protective measure developed by children as an attempt of "caring for themselves".

Keywords: Childhood, trauma, psychoanalysis, precocious maturity

(Environnement violent, enfance perdue?)

Cet article a pour but d'analyser la constitution émotionnelle et psychique d'enfants de deux favelas de Rio de Janeiro, où ils sont constamment exposés à une réalité de peur, terreur et d'impuissance, en prenant en considération le potentiel traumatique. A partir d'une pratique clinique développée avec ces enfants, cet article discute le rôle de l'hospitalité et de l'empathie de la communauté comme facteur positif pour le développement sain de l'enfant. Néanmoins, on observe une maturité précoce qui est développée comme mesure de protection par les enfants qui essaient ainsi de "prendre soin d'eux-mêmes».

Mots clés: Enfance, trauma, psychanalyse, devéloppément precoce

(Ambiente violento, ¿infancia perdida?)

El objetivo de este artículo es investigar la constitución emocional y psíquica de niños de dos favelas de Río de Janeiro, en donde son constantemente expuestos a una realidad de miedo, terror y abandono, y el potencial traumático debe ser considerado. Basado en una práctica clínica desarrollada con estos niños, el artículo discute el papel de la hospitalidad y la empatía proporcionadas por la comunidad que parecen contribuir a un desarrollo saludable. Sin embargo, un desarrollo emocional precoz puede ser visto como una medida de protección desarrollada por los niños en un intento de "cuidar sabiamente de si mismos".

Palabras clave: Infancia, trauma, psicoanálisis, desarrollo emocional precoz

(Führt eine von Gewalt geprägte Umgebung zum Verlust der Kindheit?)

Dieser Artikel erforscht die Ursachen der emotionalen und psychischen Verfassung von Kindern in zwei Favelas Rio de Janeiros, die ständig einer Wirklichkeit von Angst, Schrecken und Hilflosigkeit ausgesetzt sind, wobei das potenzielle Trauma in Betracht gezogen wird. Auf der Grundlage einer erweiterten klinischen Praxis die diese Kinder einbezieht, erläutert dieser Artikel die Rolle der Gastfreundschaft und Empathie der Gemeinschaft, die, so scheint es, einen Beitrag zu einer gesunden Entwicklung leisten.

Schlüsselwörter: Kindheit, Trauma, Psychoanalyse, verfrühte Reife 


\section{ARTIGO}

Citação/Citation: Vieira, A. C. D., \& Zornig, S. M. J. (2015, março). Ambiente violento, infância perdida?. Revista Latinoamericana de Psicopatologia Fundamental, 18(1), 88-101.

Editores do artigo/Editors: Manoel Tosta Berlinck e Sonia Leite

Recebido/Received: 11.2.2014/ 2.11.2014 Aceito/Accepted: 27.3.2014/3.27.2014

Copyright: (C) 2009 Associação Universitária de Pesquisa em Psicopatologia Fundamental/ University Association for Research in Fundamental Psychopathology. Este é um artigo de livre acesso, que permite uso irrestrito, distribuição e reprodução em qualquer meio, desde que o autor e a fonte sejam citados / This is an open-access article, which permits unrestricted use, distribution, and reproduction in any medium, provided the original authors and sources are credited.

Financiamento/Funding: As autoras declaram não ter sido financiadas ou apoiadas / The authors have no support or funding to report.

Conflito de interesses/Conflict of interest: As autoras declaram que não há conflito de interesses / The authors have no conflict of interest to declare.

\section{Ana Carolina Dias Vieira}

Psicanalista; Doutoranda em Psicologia Clínica pela Pontifícia Universidade Católica do Rio de Janeiro - PUC-Rio (Rio de Janeiro, RJ, Br); Mestre em Psicologia Clínica pela mesma Universidade; Diretora de Supervisão e Orientação Clínica da ONG Casa da Árvore (Rio de Janeiro, RJ, Br); membro do Instituto Cultural Freud (Rio de Janeiro, RJ, Br).

Rua Hans Staden, 10/311 - Botafogo

22281-060 Rio de Janeiro, RJ, Br

e-mail: anadiasvieira@yahoo.com.br

\section{Silvia Maria Abu-Jamra Zornig}

Psicanalista; Professora do programa de Pós-graduação em Psicologia Clínica pela Pontifícia Universidade Católica do Rio de Janeiro - PUC-Rio (Rio de Janeiro, RJ, Br); Coordenadora do Curso de Especialização em Psicologia Clínica com Crianças pela mesma Universidade, membro da Associação Universitária de Pesquisa em Psicopatologia Fundamental (São Paulo, SP, Br).

Rua Sara Vilela, 100 - Jardim Botânico

22460-180 Rio de Janeiro, RJ, Br

e-mail: silvia.zornig@terra.com.br 